Metallurgy and Materials Science

Металлургия и материаловедение

DOI: 10.17516/1999-494X-0362

УДК 669.713.76: 669.45: 669.765

\title{
Electrolytic Processing of Pb-Bi Alloy
}

\author{
Alexey A. Koroleva, \\ Sergey V. Sergeychenko ${ }^{a}$, Gennady I. Maltsev*a, \\ Roman S. Voinkov a and Konstantin L. Timofeev ${ }^{\mathrm{b}}$ \\ ${ }^{a}$ Stock Company «Uralelectromed» \\ Verkhnyaya Pyshma, Russian Federation \\ ${ }^{b}$ Non-State Educational Institution \\ of Higher Education the Technical University of UMMC \\ Verkhnyaya Pyshma, Russian Federation
}

Received 21.09.2021, received in revised form 19.10.2021, accepted 21.11.2021

\begin{abstract}
Metal bismuth is mainly produced as a by-product in the production of lead, tungsten, copper, silver, gold, tin and zinc. Approximately $90 \%$ of all extracted bismuth is obtained from lead, copper and other concentrates. The main source of bismuth is lead concentrates obtained during the processing of lead, as well as lead-zinc and other polymetallic ores. During the processing of these concentrates, bismuth almost completely enters the rough lead, from which it is removed during its refining. The most common technologies for the recovery of bismuth from lead ingots are the Kroll-Betterton process and the Betts electrolytic process. During the electrolysis of the Bi-Pb alloy, the separation of three products has been established, they are anode and cathode alloys, as well as salt melt. The complexity of pyroelectrometallurgical processing of a bismuth-poor alloy with the production of rough bismuth in one stage is confirmed, which necessitates the use of two stages of electrolysis. At the first stage of electrolysis, the anode product- $1(17.3-48.5 \%$ of the initial $\mathrm{Pb}-\mathrm{Bi}$ alloy) of the composition has been isolated,\%: 16.6-48.4 $\mathrm{Bi}$; 51.4-83.2 Pb; operational extraction,\%: 92.2-96.6 Bi; 9.8-44.4 Pb; main phases $\mathrm{Bi}_{0,3} \mathrm{~Pb}_{0,7}$ and $\mathrm{Bi}_{0,95} \mathrm{~Pb}_{0,05}$. A six-fold bismuth enrichment is achieved in the anode product. At the second stage of electrolysis of the previously isolated anode product of the composition, $\%: 26.7 \mathrm{Bi}$; $73.1 \mathrm{~Pb} ; 0.13 \mathrm{Cu} ; 0.08 \mathrm{Zn}$, the anode product-2 (28.1\% of the enriched $\mathrm{Pb}-\mathrm{Bi}$ alloy) of the composition has been separated,\%: 93.6 Bi; 4.1 Pb; 0.086 Ag; 0.0066 As; 0.006 Sb; 0.0013 Cu; $0.001 \mathrm{Sn} ; 0.0014 \mathrm{Zn}$; stage extraction,\%: 98.6 $\mathrm{Bi}$; $1.6 \mathrm{~Pb}$; main phase $\mathrm{Bi}_{0,95} \mathrm{~Pb}_{0,05}$.

As a result of pyroelectrometallurgical processing of a $\mathrm{Pb}-\mathrm{Bi}$ alloy $(\sim 10 \% \mathrm{Bi})$ with anode polarization in two stages, an anode product ( $8.7 \%$ of the initial alloy) of the composition has been isolated, $\%: \geq 93.6$ $\mathrm{Bi}$; $4.1 \mathrm{~Pb}$; extraction from the initial alloy,\%: 93.0 Bi; $0.4 \mathrm{~Pb}$ has been obtained. The following modes are recommended for pyroelectrometallurgical processing in two stages of $\mathrm{Pb}-\mathrm{Bi}$ alloy: process temperature $550-600{ }^{\circ} \mathrm{C}$; anode current density: $0.5 \mathrm{~A} / \mathrm{cm}^{2}$ at the first stage; $0.2-0.3 \mathrm{~A} / \mathrm{cm}^{2}$ at the second stage; cathode current density: $1.5 \mathrm{~A} / \mathrm{cm}^{2}$ at the first stage; $1.0 \mathrm{~A} / \mathrm{cm}^{2}$ at the second stage; operating voltage on
\end{abstract}

(C) Siberian Federal University. All rights reserved

This work is licensed under a Creative Commons Attribution-Non Commercial 4.0 International License (CC BY-NC 4.0).

* Corresponding author E-mail address: mgi@elem.ru 
the tub: at the first stage 8-12 V; at the second stage 5-8 V; the composition of the electrolyte at both stages, \%: $7 \mathrm{NaCl} ; 35 \mathrm{KCl} ; 18 \mathrm{PbCl}_{2} ; 40 \mathrm{ZnCl}_{2}$; the amount of electrolyte output for processing: at the first stage $-10 \%$ of the mass of the $\mathrm{Pb}$-Bi alloy after alkaline treatment; at the second stage $-10 \%$ of the mass of the anode product of the first stage.

Keywords: lead, bismuth, refining, anode product, ingot, electrolysis, first stage, second stage.

Citation: Korolev, A.A., Sergeychenko, S.V., Maltsev, G.I., Voinkov, R.S., Timofeev, K. L. Electrolytic processing of Pb-Bi alloy, J. Sib. Fed. Univ. Eng. \& Technol., 2021, 14(8), 930-941. DOI: 10.17516/1999-494X-0362

\title{
Электролитическая переработка
}

\section{Pb-Вi-сплава}

\author{
А.А. Королев ${ }^{\text {a }}$, С. В. Сергейченко \\ Г.И. Мальцев ${ }^{\text {a }}$, Р.С. Воинков ${ }^{\text {a }}$ К.Л. Тимофеев ${ }^{\sigma}$ \\ ${ }^{a}$ Акиионерное общество «Уралэлектромедь» \\ Российская Федерачия, Верхняя Пьима \\ ${ }^{6}$ Технический университет УГМК \\ Российская Федерация, Верхняя Пышма
}

\begin{abstract}
Аннотация. Металлический висмут главным образом производится как побочный продукт при получении свинца, вольфрама, меди, серебра, золота, олова и цинка. Из свинцовых, медных и других концентратов получают $\sim 90 \%$ всего добываемого висмута. Основной источник висмута - свинцовые концентраты, получаемые при переработке свинцовых, а также свинцовоцинковых и других полиметаллических руд. При переработке этих концентратов висмут почти полностью попадает в свинец черновой, из которого удаляется при его рафинировании. Наиболее распространенные технологии для восстановления висмута из свинцовых слитков - процесс Kroll-Betterton и электролитический процесс Betts. При электролизе $\mathrm{Bi}-\mathrm{Pb}$-сплава установлено выделение трех продуктов - анодного и катодного сплавов, а также солевого плава. Подтверждена сложность пироэлектрометаллургической переработки бедного по висмуту сплава с получением висмута чернового в одну стадию, что обусловливает необходимость использования двух стадий электролиза. На I стадии электролиза выделен анодный продукт-1 (17,3-48,5 \% от исходного $\mathrm{Pb}$-Вi-сплава) состава, $\%:$ : 16,6-48,4 Bi; 51,4-83,2 Pb; операционное извлечение, $\%$ : 92,2-96,6 Bi; $9,8-44,4 \mathrm{~Pb}$; основные фазы $\mathrm{Bi}_{0,3} \mathrm{~Pb}_{0,7}$ и $\mathrm{Bi}_{0,95} \mathrm{~Pb}_{0,05}$. В анодном продукте достигается шестикратное обогащение по висмуту. На ІІ стадии электролиза ранее выделенного анодного продукта состава,\%: $26,7 \mathrm{Bi} ; 73,1 \mathrm{~Pb} ; 0,13 \mathrm{Cu} ; 0,08 \mathrm{Zn}$, получен анодный продукт-2 (28,1 \% от обогащенного Pb-Biсплава) состава,\%: 93,6 Bi; 4,1 Pb; 0,086 Ag; 0,0066 As; 0,006 Sb; 0,0013 Cu; 0,001 Sn; 0,0014 Zn; стадиальное извлечение, $\%$ : 98,6 $\mathrm{Bi} ; 1,6 \mathrm{~Pb}$; основная фаза $\mathrm{Bi}_{0,95} \mathrm{~Pb}_{0,05}$.

В результате пироэлектрометаллургической переработки $\mathrm{Pb}-\mathrm{Bi}$ сплава ( $10 \% \mathrm{Bi})$ с анодной поляризацией в две стадии получен анодный продукт (8,7 \% от исходного сплава) состава,\%: $\geq 93,6 \mathrm{Bi} ; 4,1 \mathrm{~Pb}$; извлечение из исходного сплава,\%: 93,0 $\mathrm{Bi} ; 0,4 \mathrm{~Pb}$. Рекомендованы для пироэлектрометаллургической переработки в две стадии $\mathrm{Pb}-\mathrm{Bi}$-сплава следующие режимы: температура процесса $550-600{ }^{\circ} \mathrm{C}$; анодная плотность тока: на первой стадии $-0,5 \mathrm{~A} / \mathrm{cm}^{2}$; на второй стадии $0,2-0,3 \mathrm{~A} / \mathrm{cm}^{2}$; катодная плотность тока: на первой стадии $1,5 \mathrm{~A} / \mathrm{cm}^{2}$; на второй стадии 1,0 A/см²; рабочее напряжение на ванне: на первой стадии 8-12 В; на второй стадии 5-8 В; состав электролита на обеих стадиях, \%: $7 \mathrm{NaCl} ; 35 \mathrm{KCl} ; 18 \mathrm{PbCl}_{2} ; 40 \mathrm{ZnCl}_{2}$; количество электролита, выводимого на переработку: на первой стадии - 10 \% от массы Pb-Bi-сплава после щелочной обработки; на второй стадии - 10 \% от массы анодного продукта первой стадии.
\end{abstract}


Ключевые слова: свинец, висмут, рафинирование, анодный продукт, слиток, электролиз, первая стадия, вторая стадия.

Цитирование: Королев, А. А. Электролитическая переработка Рb-Ві-сплава / А. А. Королев, С. В. Сергейченко, Г.И. Мальцев, Р. С. Воинков, К. Л. Тимофеев // Журн. Сиб. федер. ун-та. Техника и технологии, 2021, 14(8). С. $930-941$. DOI: $10.17516 / 1999-494 X-0362$

\section{Введение}

Металлический висмут главным образом производится как побочный продукт при получении свинца, вольфрама, меди, серебра, золота, олова и цинка. Из свинцовых, медных и других концентратов получают 90 \% всего добываемого висмута [1-5]. Основной источник висмута свинцовые концентраты, получаемые при переработке свинцовых, а также свинцово-цинковых и других полиметаллических руд. Они содержат несколько сотых процента висмута, иногда до $0,2 \%$ Bi. При переработке этих концентратов висмут почти полностью попадает в свинец черновой, из которого удаляется при его рафинировании. Около 90-95 \% висмута производится при рафинировании свинца [6-10]. При выплавке меди висмут, наряду со свинцом, частично переходит в пыль и возгоны и отправляется потом на рафинировочные заводы для дальнейшего восстановления. Наиболее распространенные технологии для восстановления висмута из свинцовых слитков - процесс Kroll-Betterton[11-15] и электролитический процесс Betts[16-20].

Электролитический процесс Betts применяется для обработки свинцового слитка, содержащего $\sim 90$ \% Рb. Свинцовые слитки переплавляются в аноды и устанавливаются параллельно в гальваническом элементе; чистые свинцовые листы подвешиваются между анодами. Электролитом является раствор флюоросиликата или флюосиликата свинца наряду с небольшим количеством клея, обеспечивающим качество формирования катода. Когда ток пропускается через раствор, свинец на анодах растворяется, оседая на катодах. Висмут, медь и другие металлы не переходят к катоду и формируют анодную слизь, которая собирается, промывается и расплавляется для получения шлама. Шлам перемешивается с серой и углеродом с получением концентрата, содержащего 20-25 \% висмута, который восстанавливают с едким натром и селитрой, для производства 99,995 \% висмута [21-25].

Целью работы являлось определение основных параметров переработки $\mathrm{Pb}-\mathrm{Bi}$-сплавов электрометаллургическим способом с использованием электрохимической ячейки, основу которой составляет графитовый тигель с коаксиально расположенным внутри него тиглем меньшей вместимости из кварцевого стекла или алунда.

\section{Методика исследований}

В кольцевое (анодное) пространство, образованное стенками тиглей, закладывали навеску $\mathrm{Pb}$-Вi-сплава (50-100 г), внутрь кварцевого тигля (катодное пространство) - первоначальную загрузку гранулированного свинца. Затем в графитовый тигель засыпали смесь предварительно высушенных солей, включающую,\%: $7 \mathrm{NaCl} ; 35 \mathrm{KCl} ; 18 \mathrm{PbCl}_{2} ; 40 \mathrm{ZnCl}_{2}$. Тигли с содержимым помещали в электропечь сопротивления с углеграфитовым нагревателем, доводили температуру до $\sim 550^{\circ} \mathrm{C}$ с поддержанием ее на этом уровне. В дно кварцевого тигля упирали катодный токоподвод, присоединенный к отрицательному полюсу источника постоянного тока. Анодным токоподводом служила нихромовая проволока, присоединенная к положительному 
полюсу источника тока, которую закрепляли на верхней кромке графитового тигля. В течение заданного промежутка времени через ячейку пропускали постоянный электрический ток. Продолжительность процесса ( $\tau$, мин), определяемая количественным переносом свинца из анодного сплава в катодное пространство, рассчитывали по формуле

$$
\tau=0,01 m C_{\mathrm{Pb}}\left(60 A_{3} I\right)^{-1},
$$

где $m$ - масса $\mathrm{Pb}$-Вi-сплава, г; $C_{\mathrm{Pb}}$ - содержание свинца в $\mathrm{Pb}$-Ві-сплаве, $\%$; $A_{\ni}$ - электрохимический эквивалент свинца, г КК ${ }^{-1}\left(\mathrm{~A}_{э}=0,001074 \Gamma \cdot \mathrm{K}^{-1}\right) ;-$ сила тока, $A$.

Потребную токовую нагрузку находили по выражению

$$
I=j_{\mathrm{a}} S_{1},
$$

где $j_{\mathrm{a}}$ - анодная плотность тока, $\mathrm{A} / \mathrm{cm}^{2}\left(j_{\mathrm{a}}=0,25-0,50 \mathrm{~A} / \mathrm{cm}^{2}\right) ; S_{1}$ - площадь зеркала анодного расплава, см² $\left(S_{1}=18,6-19,7\right.$ см$\left.^{2}\right)$.

Электролиз вели в гальваностатическом $(I=$ const) режиме, каждые 5-10 мин фиксируя показания амперметра и вольтметра. По истечении заданного времени отключали ток и охлаждали ячейку в печи, определяли химический состав продуктов. По результатам эксперимента рассчитывали основные показатели электролиза. Интегральное рабочее напряжение $\left(U_{\mathrm{p}}^{\Sigma}, \mathrm{B}\right)$ оценивали по выражению

$$
U_{\mathrm{p}}^{\Sigma}=0,5 \tau^{-1}\left(U_{\mathrm{n}}{ }^{\mathrm{H}}+U_{\mathrm{n}}{ }^{\mathrm{K}}\right) \Delta \tau_{\mathrm{n}},
$$

где $U_{\mathrm{n}}{ }^{\mathrm{H}}$ и $U_{\mathrm{n}}{ }^{\mathrm{k}}-$ значения мгновенного напряжения в моменты начала и конца $n$-го интервала времени, В; $\tau$ - длительность $n$-го интервала времени, мин.

Аналогичным образом оценивали интегральную токовую нагрузку $I_{\mathrm{p}}^{\Sigma}, \mathrm{A}$ :

$$
I_{\mathrm{p}}^{\Sigma}=0,5 \tau^{-1}\left(I_{\mathrm{n}}{ }^{\mathrm{H}}+I_{\mathrm{n}}{ }^{\mathrm{K}}\right) \Delta \tau_{\mathrm{n}},
$$

где $I_{\mathrm{n}}{ }^{\mathrm{H}}$ и $I_{\mathrm{n}}{ }^{\mathrm{K}}-$ значения мгновенной силы тока в моменты начала и конца $n$-го интервала времени, А.

Катодную плотность тока $j_{\text {к }}$ рассчитывали по формуле, $\mathrm{A} / \mathrm{cm}^{2}$,

$$
j_{\mathrm{K}}=I_{\mathrm{p}}^{\sum} S_{2}^{-1}
$$

где $S_{2}$ - площадь зеркала катодного расплава, см² $\left(S_{2}=6,6 \mathrm{~cm}^{2}\right)$.

Анодный выход по току ( $\left.\eta_{a}, \%\right)$ определяли по выражению

$$
\eta_{\mathrm{a}}=100 \Delta m_{\mathrm{a}}\left(60 A_{\ni} I_{\mathrm{p}}{ }^{\Sigma} \tau\right)^{-1},
$$

где $\Delta m_{\mathrm{a}}$ - разница масс исходного $\mathrm{Pb}-\mathrm{Bi}$-сплава и анодного продукта, г.

Катодный выход по току $\eta_{\mathrm{a}}, \%$ :

$$
\eta_{\mathrm{\kappa}}=100 \Delta m_{\mathrm{K}}\left(60 A_{9} I_{\mathrm{p}}^{\Sigma} \tau\right)^{-1},
$$

где $\Delta m_{\text {к }}$ - разница масс катодного продукта и исходного количества $\mathrm{Pb}$, г.

Удельный расход электроэнергии по свинцу $W_{\text {уд }}{ }^{\mathrm{Pb}}$, кВт·ч/(т Pb):

$$
W_{\text {уд }}^{\mathrm{Pb}}=10^{3} I_{\mathrm{p}}^{\Sigma} U_{\mathrm{p}}^{\Sigma} \tau\left(60 \Delta m_{\mathrm{a}}\right)^{-1} \text {. }
$$


Удельный расход электроэнергии по висмуту $W_{\text {уд }}^{\text {Bi }}$, кВт·ч/(т Вi):

$$
W_{\text {уд }}{ }^{\mathrm{Bi}}=10^{3} I_{\mathrm{p}}{ }^{\Sigma} U_{\mathrm{p}}^{\Sigma} \tau\left(0,6 m_{\mathrm{a}} \mathrm{C}_{\mathrm{a}}{ }^{\mathrm{Bi}}\right)^{-1},
$$

где $m_{\mathrm{a}}$ - масса анодного продукта, г; $\mathrm{C}_{\mathrm{a}}^{\mathrm{Bi}}$ - содержание Вi в анодном продукте, $\%$.

Предполагалось, что электролитическая переработка $\left(j_{\mathrm{a}}=0,5 \mathrm{~A} / \mathrm{cm}^{2}\right)$ Pb-Вi-сплава состава,\%: 8,7 $\mathrm{Bi}$; 91,0 Pb, в смеси расплавленных хлоридов натрия, калия, свинца и цинка (загрузка - 223-283 \% от количества $\mathrm{Pb}$-Вi-сплава), проведенная в интервале времени, достаточного для полного анодного растворения содержащегося в нем свинца по реакции

$$
\mathrm{Pb}-2 \mathrm{e}^{-}=\mathrm{Pb}^{2+},
$$

приведет к получению анодного продукта, содержащего более 90 \% Bi.

Основным сопутствующим катодным процессом должен был являться разряд ионов $\mathrm{Pb}^{2+}$ на поверхности расплавленного свинца:

$$
\mathrm{Pb}^{2+}+2 \mathrm{e}^{-}=\mathrm{Pb}
$$

\section{Обсуждение результатов}

При электролизе показана возможность выделения трех продуктов - анодного и катодного сплавов, а также солевого плава. Выявлено существенное отличие полученных составов продуктов от прогнозируемых, что подтверждает сложность получения висмута чернового пироэлектрометаллургическим способом в одну стадию (табл. 1, 2). Поэтому опыты по переработке бедного по висмуту сплава (опыт 1,2 ) условно отнесены к первой стадии электролиза. Выделенный на этой стадии анодный продукт (выход 17,3-48,5 \% от исходного $\mathrm{Pb}$-Вi-сплава) содержит,\%: 16,6-48,4 Bi; 51,4-83,2 Pb. Операционное извлечение составляет\%: 92,2-96,6 Bi; 9,8-44,4 Pb. Из дифрактограммы анодного продукта І стадии электролиза $\mathrm{Pb}-\mathrm{Bi}$-сплава основными фазами являются $\mathrm{Bi}_{0,3} \mathrm{~Pb}_{0,7} ; \mathrm{Bi}_{0,95} \mathrm{~Pb}_{0,05}$. В катодный продукт I стадии электролиза $\mathrm{Pb}-\mathrm{Bi}$ сплава (67,5-78,7 \% от Pb-Вi-сплава), содержащий,\%: 0,005 Bi; 97,2 Pb, переходит $\sim 0,05 \%$ Bi и $56,2 \% \mathrm{~Pb}$. Катодный продукт состоит из элементных свинца и цинка. Часть целевых металлов $(0,9 \% \mathrm{Bi} ; 46,8-68,8 \% \mathrm{~Pb})$ сконцентрирована в солевом плаве, отличающемся повышенным выходом (253,2-300,4 \% от Рb-Ві-сплава), содержащем,\%: 0,03 Bi; 26,8-36,6 Pb. Основные фазы солевого плава: $\mathrm{KPb}_{2} \mathrm{Cl}_{5} ; \mathrm{K}_{2} \mathrm{~Pb}_{2} \mathrm{O}_{4} ; \mathrm{KCl}$.

В процессе электролиза выявлена первоначальная стабилизация рабочего напряжения в диапазоне 7,42-9,75 В (рис. 1), характерная для пироэлектрометаллургической переработки $\mathrm{Pb}-\mathrm{Bi}$-сплавов $[26,27]$. По мере продолжения электролиза напряжение (U, B) увеличивается: в опытах 1/2: $(10,88-14,53) /(11,20-15,58)$.

Рост рабочего напряжения можно пояснить скачком катодного потенциала, связанным с началом восстановления щелочных металлов [28]; параллельно возникают условия, благоприятные для разряда катионов цинка [29]:

$$
\mathrm{Na}^{+}+\mathrm{e}^{-}=\mathrm{Na} ; \mathrm{Zn}^{2+}+2 \mathrm{e}^{-}=\mathrm{Zn} .
$$

О протекании реакций свидетельствуют повышенные содержания упомянутых металлов в катодном продукте, \%: 3,7 Zn; 20,1 Na. 
Таблица 1. Параметры электролиза I и II стадии Pb-Bi-сплава

Table 1. Parameters of electrolysis of the I and II stages of $\mathrm{Pb}$-Bi alloy

\begin{tabular}{|c|c|c|}
\hline \multirow[b]{2}{*}{ Наименование показателя } & \multicolumn{2}{|c|}{ Стадия электролиза } \\
\hline & $\begin{array}{c}\text { Первая } \\
\text { (опыт } 1 / 2 \text { ) } \\
\end{array}$ & $\begin{array}{l}\text { Вторая } \\
\text { (опыт3) }\end{array}$ \\
\hline Масса свинцово-висмутового сплава, г & $80,7 / 61,6$ & 42,6 \\
\hline Содержание Ві в свинцово-висмутовом сплаве, $\%$ & $8,7 / 8,7$ & 26,7 \\
\hline Содержание Рb в свинцово-висмутовом сплаве, $\%$ & $91,0 / 91,0$ & 73,1 \\
\hline Масса первоначальной катодной загрузки Рb-гранул, г & $20,5 / 20,5$ & 20,5 \\
\hline Масса навески смеси солей, г & $180,6 / 174,4$ & 268,5 \\
\hline Загрузка смеси сухих солей,\% от Pb-Bi-сплава & $223 / 283$ & 630 \\
\hline Температура процесса, ${ }^{\circ} \mathrm{C}$ & $550 / 550$ & 550 \\
\hline Заданная сила тока, А & $9,9 / 9,3$ & 5,6 \\
\hline Заданная анодная плотность тока, $\mathrm{A} / \mathrm{cm}^{2}$ & $0,5 / 0,5$ & 0,3 \\
\hline Продолжительность электролиза, мин & $116 / 93$ & 86 \\
\hline Интегральное рабочее напряжение, В & $9,4 / 10,1$ & 8,0 \\
\hline Интегральная токовая нагрузка, А & $9,5 / 9,3$ & 6,8 \\
\hline Масса анодного продукта, г & $13,95 / 29,90$ & 11,97 \\
\hline Содержание Ві в анодном продукте,\% & $48,4 / 16,6$ & 93,6 \\
\hline Содержание $\mathrm{Pb}$ в анодном продукте,\% & $51,4 / 83,2$ & 4,1 \\
\hline Масса катодного продукта, г & $63,50 / 41,58$ & 56,48 \\
\hline Масса металлов, перешедших в катодный продукт, г & $43,0 / 21,1$ & 36,0 \\
\hline Масса металлов, перешедших в солевой плав, г & $23,8 / 10,6$ & - \\
\hline Масса солевого плава, г & $204,4 / 185,0$ & 263,2 \\
\hline Выход анодного продукта от Pb-Bi-сплава,\% & $17,3 / 48,5$ & 28,1 \\
\hline Выход катодного продукта от Pb-Bi-сплава,\% & $78,7 / 67,5$ & 132,5 \\
\hline Выход солевого плава от Pb-Ві-сплава,\% & $253,2 / 300,4$ & 617,6 \\
\hline Извлечение висмута в анодный продукт из Pb-Bi-сплава,\% & $96,0 / 92,2$ & 98,6 \\
\hline Извлечение висмута в катодный продукт из Pb-Bi-сплава, \% & $0,05 /-$ & 0,2 \\
\hline Извлечение свинца в анодный продукт из Pb-Bi-сплава,\% & $9,8 / 44,4$ & 1,6 \\
\hline Извлечение свинца а в катодный продукт из Pb-Bi-сплава,\% & $56,2 /-$ & 111,5 \\
\hline Извлечение висмута в солевой плав из Pb-Вi-сплава,\% & $0,9 /-$ & 0,1 \\
\hline Извлечение свинца в солевой плав из Pb-Bi-сплава,\% & $68,8 / 46,8$ & 2,0 \\
\hline Анодный выход по току,\% & $94,5 / 56,6$ & 80,9 \\
\hline Катодный выход по току,\% & $60,9 / 37,6$ & 94,9 \\
\hline Удельный расход электроэнергии по свинцу, кВт · ч/(т свинца) & $2584 / 4631$ & 2557 \\
\hline Удельный расход электроэнергии по висмуту, кВт · ч/(т висмута) & $25535 / 29645$ & 6995 \\
\hline
\end{tabular}

Что касается основных параметров и показателей первой стадии электролиза, то их значения удовлетворительно согласуются с известными данными [30, 31]. Интегральная токовая нагрузка составляет 9,3-9,5 А, интегральное рабочее напряжение - 9,4-10,1 В. Фактические средние анодная и катодная плотности тока находились на уровне 0,5 и 1,4-1,5 A/см ${ }^{2}$ соответственно. Анодный выход по току равен 56,6-94,5 \%. Несколько меньшая величина катодного 


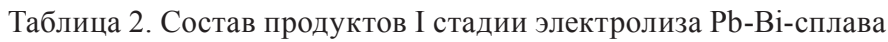

Table 2. Composition of products of the first stage of electrolysis of $\mathrm{Pb}-\mathrm{Bi}$ alloy

\begin{tabular}{|c|c|c|c|c|c|}
\hline \multirow{2}{*}{ Элемент } & \multicolumn{5}{|c|}{ Содержание, $\%$} \\
\cline { 2 - 6 } & \multicolumn{3}{|c|}{ Опыт 1} & \multicolumn{2}{c|}{ Опыт 2} \\
\cline { 2 - 6 } & $\begin{array}{c}\text { Анодный } \\
\text { продукт }\end{array}$ & $\begin{array}{c}\text { Катодный } \\
\text { продукт }\end{array}$ & $\begin{array}{c}\text { Солевой } \\
\text { плав }\end{array}$ & $\begin{array}{c}\text { Анодный } \\
\text { продукт }\end{array}$ & $\begin{array}{c}\text { Солевой } \\
\text { плав }\end{array}$ \\
\hline $\mathrm{Bi}$ & 48,43 & 0,0050 & 0,0300 & 16,563 & 0,108 \\
\hline $\mathrm{Cu}$ & 0,106 & 0,0009 & 0,0095 & 0,139 & 15,629 \\
\hline $\mathrm{K}$ & & 0,0100 & 17,9100 & & 0,395 \\
\hline $\mathrm{Na}$ & & 0,0129 & 3,2140 & & 26,814 \\
\hline $\mathrm{Pb}$ & 51,422 & 97,229 & 36,550 & 83,194 & 14,490 \\
\hline $\mathrm{Zn}$ & 0,042 & 2,6790 & 8,2870 & 0,104 & \\
\hline
\end{tabular}

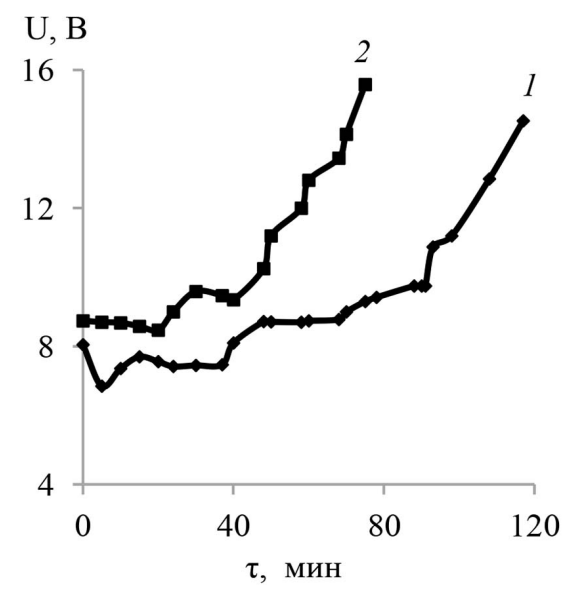

Рис. 1. Зависимость $U$ от продолжительности I стадии электролиза Pb-Ві-сплава: 1 - опыт $1 ; 2$ - опыт 2

Fig. 1. Dependence of $U$ on the duration of the I stage of electrolysis of Pb-Bi alloy: 1-experience 1; 2-experience 2

выхода по току (37,6-60,9 \%) связана с накоплением свинца в солевом плаве, подтверждаемом ростом в последнем массовой доли этого металла с 13,4 до 36,6 \%. Удельный расход электроэнергии по свинцу достигает 2583-4631 кВт·ч/(т Рb); для висмута (учитывая его меньшее содержание) этот показатель значительно выше: 25535-29645 кВт·ч/(т Вi). Полученные результаты указывают на то, что пироэлектрометаллургическая переработка бедных по висмуту $\mathrm{Pb}-\mathrm{Bi}$ сплавов, проводимая в одну стадию, позволяет сконцентрировать висмут в анодном продукте при его шестикратном обогащении (до 50 \% Ві). Возгонка хлоридов, окисление свинца воздухом до оксидов и сокращение площади анодной поверхности обусловливают скачок рабочего напряжения, приводящий к восстановлению катионов цинка и натрия, что нарушает штатный ход процесса. Ожидалось, что повторная электролитическая переработка обогащенного висмутом сплава в свежем электролите (при увеличении единовременной загрузки смеси солей до 630 \% от указанного сплава) приведет к получению анодного продукта желаемого качества. В связи с этим в опыте 3 (табл. 1) в анодное пространство загрузили навеску полученных ранее

$$
-936-
$$


анодных продуктов первой стадии электролиза. Расчетный средневзвешенный химический состав объединенного сплава,\%: 26,7 Bi; 73,1 Pb; 0,13 Cu; 0,08 Zn. Для снижения рабочего напряжения и, соответственно, токовой нагрузки величину задаваемой анодной плотности тока снизили до $0,3 \mathrm{~A} / \mathrm{cm}^{2}$. Осуществление второй стадии электролиза подтверждает высказанное предположение и указывает на возможность получения трех стандартных продуктов: анодного и катодного сплавов, а также солевого плава. Анодный продукт (выход 28,1 \% от обогащенного свинцово-висмутового сплава) содержит,\%: 93,6 Bi; 4,1 Pb; 0,086 Ag; 0,0066 As; 0,006 Sb; 0,0013 $\mathrm{Cu}$; 0,001 Sn; 0,0014 Zn; стадиальное извлечение - 98,6 \% Вi и 1,6 \% Pb. Основная фаза сплава $-\mathrm{Bi}_{0,95} \mathrm{~Pb}_{0,05}$.

В катодный продукт (132,5 \% от обогащенного $\mathrm{Pb}$-Вi-сплава), содержащий 0,033 \% $\mathrm{Bi}$ и $97,83 \% \mathrm{~Pb}$, переходит около $0,2 \% \mathrm{Bi}$ и $111,5 \% \mathrm{~Pb}$ (превышение последним показателем уровня в $100 \%$ свидетельствует о протекании процессов восстановления собственных ионов $\mathrm{Pb}^{2+}$ электролита). Основные фазы - элементные свинец и цинк. Солевой плав (617,6 \% от обогащенного свинцово-висмутового сплава) концентрирует $0,1 \%$ висмута при его содержании $0,003 \%$. Основные фазы плава: $\mathrm{K}_{2} \mathrm{ZnCl}_{4}, \mathrm{ZnCl}_{2}, \mathrm{NaCl}, \mathrm{KCl}$. Отмечено обеднение солевого плава по свинцу с 13,4 до 0,24 \% масс., связанное с протеканием катодного процесса.

На 71-й минуте процесса отмечен резкий скачок рабочего напряжения (рис. 2), причину которого установить не удалось, в дальнейшем ход процесса стабилизировался: интегральная токовая нагрузка составила 6,8 А, интегральное рабочее напряжение - 8,0 В, что несколько ниже, чем на первой стадии. По этой причине меньшие значения имели фактические средние анодная и катодная плотности тока - 0,4 и 1,0 A/см² соответственно. Анодный выход по току достигает 80,9 \%. Повышенный катодный выход по току $(94,9$ \%) пояснен интенсивным разрядом на отрицательном электроде ионов $\mathrm{Pb}^{2+}$ электролита. Удельный расход электроэнергии по свинцу, как и на первой стадии, достигает 2557 кВт·ч/(т Pb), для висмута он существенно снизился - до 6995 кВт·ч/(т Ві).

Установлено, что пироэлектрометаллургическая переработка с анодной поляризацией $\mathrm{Pb}-\mathrm{B}$-сплава (до $\sim 10 \%$ Вi) в две стадии ведет к получению анодного продукта (выход 8,7 \%

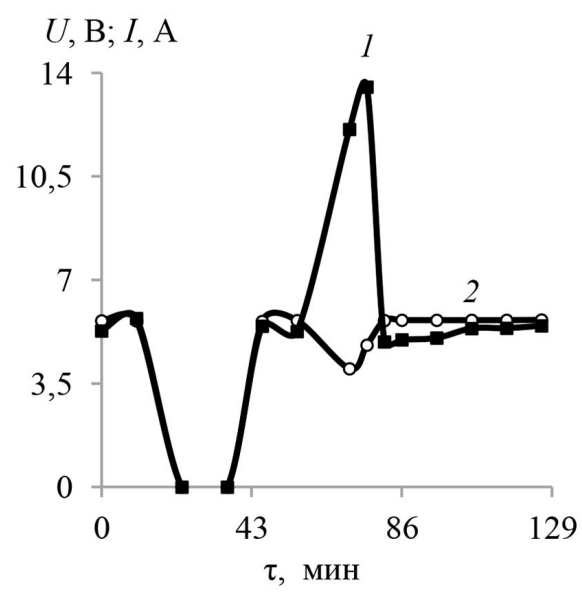

Рис. 2. Зависимость $U(1)$ и $I(2)$ от продолжительности II стадии электролиза $\mathrm{Pb}$-Bi-сплава

Fig. 2. Dependence of $U(1)$ and $I$ (2) on the duration of the II stage of electrolysis of Pb-Bi alloy 
от исходного сплава), близкого по качеству к висмуту черновому, содержащему (\%) не менее 93,6 $\mathrm{Bi}$ и 4,1 $\mathrm{Pb}$, согласно диаграмме состояния $\mathrm{Bi}-\mathrm{Pb}$-сплава [32]. Извлечение в указанный продукт целевых металлов из исходного сплава,\%: 93,0 Bi; 0,4 Pb. Выход катодного продукта (без учета первоначальной загрузки свинца) - 25,3 \% от исходного Pb-Bi-сплава, в него переходит до 7,0 \% Вi и 23,7 \% Pb. Часть металлов выводится с солевым плавом. Объем солевого расплава, подлежащего выводу на переработку и замене на свежий электролит, - до 10 \% от массы анодной загрузки.

По результатам эксперимента апробацию в опытно-промышленном масштабе пироэлектрометаллургической переработки в две стадии $\mathrm{Pb}-\mathrm{Bi}-$ сплава, полученного после реагентной обработки висмутистого свинца, рекомендованы следующие режимы: температура процесса $550-600{ }^{\circ} \mathrm{C}$; анодная плотность тока: на первой стадии $0,5 \mathrm{~A} / \mathrm{cm}^{2}$; на второй стадии $0,2-0,3 \mathrm{~A} / \mathrm{cm}^{2}$; катодная плотность тока: на первой стадии $1,5 \mathrm{~A} / \mathrm{cm}^{2}$; на второй стадии $1,0 \mathrm{~A} / \mathrm{cm}^{2}$; рабочее напряжение на ванне: на первой стадии 8-12 В; на второй стадии 5-8 В; состав электролита на обеих стадиях,\%: $7 \mathrm{NaCl} ; 35 \mathrm{KCl} ; 18 \mathrm{PbCl}_{2} ; 40 \mathrm{ZnCl}_{2}$; количество электролита, выводимого на переработку: на первой стадии $10 \%$ от массы $\mathrm{Pb}-\mathrm{Bi}$ сплава после щелочной обработки; на второй стадии 10 \% от массы анодного продукта первой стадии.

\section{Выводы}

При электролизе $\mathrm{Bi}-\mathrm{Pb}$-сплава установлено выделение трех продуктов - анодного и катодного сплавов, а также солевого плава. Подтверждена сложность пироэлектрометаллургической переработки бедного по висмуту сплава с получением висмута чернового в одну стадию, что обусловливает необходимость использования двух стадий электролиза.

На I стадии электролиза выделен анодный продукт-1 (17,3-48,5 \% от исходного $\mathrm{Pb}-\mathrm{Bi}$ сплава) состава,\%: 16,6-48,4 Bi; 51,4-83,2 Pb; операционное извлечение,\%: 92,2-96,6 Bi; 9,8$44,4 \mathrm{~Pb}$; основные фазы $\mathrm{Bi}_{0,3} \mathrm{~Pb}_{0,7}$ и $\mathrm{Bi}_{0,95} \mathrm{~Pb}_{0,05}$. В анодном продукте достигается шестикратное обогащение по висмуту.

На II стадии электролиза ранее выделенного анодного продукта состава,\%: 26,7 Bi; 73,1 Pb; $0,13 \mathrm{Cu} ; 0,08 \mathrm{Zn}$, получен анодный продукт-2 (28,1 \% от обогащенного Рb-Ві-сплава) состава,\%: 93,6 Bi; 4,1 Pb; 0,086 Ag; 0,0066 As; 0,006 Sb; 0,0013 Cu; 0,001 Sn; 0,0014 Zn; стадиальное извлечение, \%: 98,6 $\mathrm{Bi} ; 1,6 \mathrm{~Pb}$; основная фаза $\mathrm{Bi}_{0,95} \mathrm{~Pb}_{0,05}$.

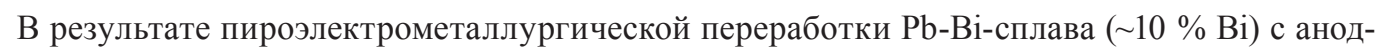
ной поляризацией в две стадии получен анодный продукт (8,7 \% от исходного сплава) состава,\%: $\geq 93,6 \mathrm{Bi} ;$ 4,1 Pb; извлечение из исходного сплава,\%: 93,0 Bi; 0,4 Pb.

\section{Список литературы / References}

[1] Liu W., Li W., Han J., Wu D., Li Z., Gu K., Qin W. Preparation of calcium stannate from lead refining slag by alkaline leaching-purification-causticization process, Separation and Purification Technology, 2019, 212, 119-125.

[2] Wu D., Liu W., Han J., Jiao F., Xu J., Gu K., Qin W. Direct preparation of sodium stannate from lead refining dross after $\mathrm{NaOH}$ roasting-water leaching, Separation and Purification Technology, 2019, 227, 115683. 
[3] Zhang X., Friedrich S., Friedrich B. Separation behavior of arsenic and lead from antimony during vacuum distillation and zone refining, Journal of Materials Research and Technology, 2020, 9(3), 4386-4398.

[4] Zhang Y., Deng J., Jiang W., Mei Q., Liu D. Application of vacuum distillation in refining crude lead, Vacuum, 2018, 148, 140-148.

[5] Lewis A.E., Beautement C. Prioritising objectives for waste reprocessing: a case study in secondary lead refining, Waste Management, 2002, 22(6), 677-685.

[6] Frolova I. V., Tikhonov V. V., Nalesnik O. I., Streltsova A. A. The Enrichment of Stale Tailings of Bom-gorhon Tungsten Ore Deposits, Procedia Chemistry, 2014, 10, 364-368.

[7] Henckens T. Scarce mineral resources: Extraction, consumption and limits of sustainability, Resources, Conservation and Recycling, 2021, 169, 105511.

[8] Wu S., Mao J., Ireland T. R., Zhao Z., Yao F., Yang Y., Sun W. Comparative geochemical study of scheelite from the Shizhuyuan and Xianglushan tungsten skarn deposits, South China: Implications for scheelite mineralization, Ore Geology Reviews, 2019, 109, 448-464.

[9] Myint A.Z., Yonezu K., Boyce A.J., Selby D., Scherstén A., Tindell T., Watanabe K., Swe Y.M. Stable isotope and geochronological study of the Mawchi Sn-W deposit, Myanmar: Implications for timing of mineralization and ore genesis, Ore Geology Reviews, 2018, 95, 663-679.

[10] Hausen D. M. Process mineralogy applied to exploration, development and exploitation of select Tungsten Ores, Ore Geology Reviews, 1989, 4(3), 201-230.

[11] Mallaley K., Morris D.R. Analysis of the Betterton-Kroll process: the removal of bismuth from lead bullion, Primary and Secondary Lead Processing. Proceedings of the International Symposium on Primary and Secondary Lead Processing, Halifax, Nova Scotia, August 20-24, 1989. Proceedings of Metallurgical Society of Canadian Institute of Mining and Metallurgy, 1989, 253-262.

[12] Lu D.-k., Jin Z.-n., Jiang K.-x. Fine debismuthizing with calcium, magnesium and antimony, Transactions of Nonferrous Metals Society of China, 2011, 21(10), 2311-2316.

[13] Lu D.-k., Jin Z.-n., Chang Y.-f., Sun S.-c. Mechanism of debismuthizing with calcium and magnesium, Transactions of Nonferrous Metals Society of China, 2013, 23(5), 1501-1505.

[14] Hibbins S. G., Closset B., Bray M. Advances in the refining and alloying of lowbismuth lead, Journal of Power Sources, 1995, 53(1), 75-83.

[15] Appendix B. Description of metal production flowcharts, Developments in Mineral Processing, 2005, 16, 557-647.

[16] Zhang X., Pan J., Sun Y., Feng Y., Niu H. An energy saving and fluorine-free electrorefining process for ultrahigh purity lead refining, Chinese Journal of Chemical Engineering, 2019, 27(5), 1191-1199.

[17] Babanova S., Santoro C., Jones J., Phan T., Serov A., Atanassov P., Bretschger O. Practical demonstration of applicability and efficiency of platinum group metal-free based catalysts in microbial fuel cells for wastewater treatment, Journal of Power Sources, 2021, 491, 229582.

[18] Tan S.-y., Hallett J.P., Kelsall G. H. Electrodeposition of lead from methanesulfonic acid and methanesulfonate ionic liquid derivatives, Electrochimica Acta, 2020, 353, 136460.

[19] Cvetkovicv S., Vukicevicn M., Stevanovicj S., Jovicevicj N. Aluminium electrodeposition under novel conditions from $\mathrm{AlCl}_{3}$-urea deep eutectic solvent at room temperature, Transactions of Nonferrous Metals Society of China, 2020, 30(3), 823-834.

$$
-939-
$$


[20] Ghergari L., Oniciu L., Mureşan L., Pântea A., Topan V. A., Gherţoiu D. Effect of additives on the morphology of lead electrodeposits, Journal of Electroanalytical Chemistry and Interfacial Electrochemistry, 1991, 313(1-2), 303-311.

[21] Yang J.-g., Tang C.-b., Yang S.-h., He J., Tang M.-t. The separation and Electrowinning of bismuth from a bismuth glance concentrate using a membrane cell, Hydrometallurgy, 2009, 100(1-2), $5-9$.

[22] Che J., Chen Y.,. Ma B.,, Wang C.,. Zhang W. Recovery of metallic Bi from Pb-Bi slag: An integrated process of chloride leaching and electrowinning, Hydrometallurgy, 2020, 193, 105321.

[23] Davenport W. G., King M., Schlesinger M., Biswas A.K. Chapter 16: Electrolytic Refining, Extractive Metallurgy of Copper, 2002, 265-288.

[24] Способ электролитического рафинирования висмута: пат. 2051991 Рос. Федерация: C25C1/22 / М.А. Соловьев, В.А. Куликов; патентообладатель Курганский государственный педагогический институт. № 92 5039274, заявл. 25.02.1992; опубл. 20.06.2000. [The method of electrolytic refining of bismuth: pat. 2051991 Ros. Federation: C25C1/22 / M. A. Solovyov, V. A. Kulikov; patent holder Kurgan State Pedagogical Institute. No. 925039274 , declared on 25.02.1992; published on 20.06.2000 (in Russian)].

[25] Способ отделения висмута от свинща: пат. 2049158 Рос. Федерация: C25C1/22, C25C1/18 / А. А. Смольков, М.А. Медков, Б. Н. Захаров; заявитель Производственное объединение «Дальполиметалл», патентообладатель Институт химии Дальневосточного отделения РАН. № 5065121/02, заявл. 14.08.1992; опубл. 27.11.1995. [The method of separating bismuth from lead: pat. 2049158 Ros. Federation: C25C1/22, C25C1/18 / A. A. Smolkov, M. A. Medkov, B. N. Zakharov; applicant Production Association «Dalpolymetal», patent holder Institute of Chemistry of the Far Eastern Branch of the Russian Academy of Sciences. No. 5065121/02, application No. 14. 08. 1992; publ. 27.11.1995(in Russian)].

[26] Морачевский А.Г. Физико-химия рециклинга свинца. СПб.: Издательство Политехнического университета, 2009. 270 с. [Morachevsky A. G. Physico-chemistry of lead recycling, St. Petersburg, Polytechnic University Publishing House, 2009, 270 p. (in Russian)]

[27] Теут А.О., Клименко В.В. Технология получения товарного висмута из промпродуктов свинцового производства, Цветная металлургия, 2012, 5, 32-36. [Teut A.О., Klimenko V.V. Technology of obtaining commercial bismuth from industrial products of lead production, Non-ferrous Metallurgy, 2012, 5, 32-36 (in Russian)].

[28] Зайков Ю.П. Электрохимия расплавленных солей. Екатеринбург: Издательство Уральского университета, 2014. 65 c. [Zaikov Yu. P. Electrochemistry of molten salts. Yekaterinburg: Ural University Publishing House, 2014. 65 p. (inRussian)].

[29] Делимарский Ю. К., Зарубицкий О. Г. Получение висмута и свинца электролизом расплавленных солей, Украинский химический журнал, 1981, 47(11), 1138-1148. [Delimarsky Yu.K., Zarubitsky O. G. Preparation of bismuth and lead by electrolysis of molten salts, Ukrainian Chemical Journal, 1981, 47(11), 1138-1148. (in Russian)].

[30] Зарубицкий О. Г., Омельчук А. А., Будник В. Г. Получение свинца и висмута электролизом в хлоридных расплавах, Цветные металлы, 1978, 6, 14-17. [Zarubitsky O. G., Omelchuk A. А., Budnik V. G. Production of lead and bismuth by electrolysis in chloride melts, Non-ferrous Metals, 1978, 6, 14-17, (in Russian)]. 
[31] Делимарский Ю.К., Зарубицкий О. Г. Возможности и перспективы применения методов электролиза расплавленных солей в металлургии тяжелых цветных металлов, Ионные расплавы, 1975, 3, 22-40. [Delimarsky Yu. K., Zarubitsky O. G. Possibilities and prospects of application of methods of electrolysis of molten salts in metallurgy of heavy non-ferrous metals, Ionic melts, 1975, 3, 22-40, (in Russian)].

[32] Лякишев Н.П. Диаграммы состояния двойных металлических систем. М.: Машиностроение, 1996. 992 с. [Lyakishev N.P. Diagrams of the state of double metal systems. Moscow: Mashinostroenie, 1996. 992 p.]. 